\title{
Estructura y composición de la comunidad de cianobacterias bentónicas de un arroyo de montaña mediterráneo, el arroyo Mediano (Madrid)
}

\author{
Alberto Serrano, Pilar Mateo y Elvira Perona \\ Departamento de Biología, Facultad de Ciencias, Universidad Autónoma de Madrid, Campus de \\ Cantoblanco, 28049 Madrid, España. e-mail: elvira.perona@uam.es
}

\section{RESUMEN}

La comunidad de cianobacterias bentónicas del arroyo Mediano (Comunidad de Madrid) está compuesta por 16 especies, de ellas, 4 pertenecen al orden de las Chroococcales, 9 al de las Oscillatoriales y 3 al orden Nostocales. Se han definido 7 "especies comunes" como constituyentes más representativos de esta comunidad, ya que aparecen en más del $25 \%$ de las muestras observadas, las otras 9 especies se observan con presencia puntual, habiendo sido incluidas en la categoría de "especies raras". Las "especies comunes" fueron: Chamaesiphon minutus, Chroococcus minor, Chroococcus minutus, Synechococcus elongatus, Leptolyngbya nostocorum, Phormidium aerugineo-caeruleum y Nostoc carneum. A lo largo del arroyo mediano hay variaciones en la estructura: las Chroococcales se mantienen constantes en todos los tramos del río definidos, sin embargo, en los tramos medio y bajo hay un incremento de las Oscillatoriales y un descenso de las Nostocales. Los estudios taxonómicos se realizaron utilizando dos tipos de metodologías: por un lado la observación de muestras fijadas y paralelamente muestras cultivadas en medio agarizado de cianobacterias. El $37 \%$ de los especímenes observados (todos "especies raras") se observaron únicamente en las muestras cultivadas. Se propone el empleo paralelo de ambas metodologías para realizar un estudio de una comunidad cianobacteriana como una técnica útil, además de favorecer la identificación taxonómica de algunas especies.

Palabras clave: arroyo mediterráneo, cianobacterias bentónicas, cultivos, España, comunidad, taxonomía.

\begin{abstract}
Sixteen benthic cyanobacterial species were identified in the Mediano stream (Comunidad de Madrid), among them, 4 species are Chroococcales, 9 Oscillatoriales and 3 Nostocales. Seven "common species" were defined as important members of this benthic community, since they were observed in more than $25 \%$ of all examined samples, the other 9 species showed a sporadic distribution, thus, they have been described as "rare species". Identified "common species" were Chamaesiphon minutus, Chroococcus minor, Chroococcus minutus, Synechococcus elongatus, Leptolyngbya nostocorum, Phormidium aerugineo-caeruleum and Nostoc carneum. There are some variations in community structure: while Chroococales keep constant in all defined stretches, Oscillatoriales increase their presence and Nostocales decrease in medium and low stretches. Taxonomical studies have been carried out using two different methodologies: observation of fixed and cultured samples. From the total cyanobacterial community, $37 \%$ (all belonging to "rare species"), were only seen in cultured samples. Therefore, we propose that, the combined use of both methodologies is highly useful to achieve a cyanobacterial community analysis. Additionally, it also allows an help in taxonomic identification for some species.
\end{abstract}

Keywords: benthic cyanobacteria, community, cultures, Mediterranean stream, taxonomy, Spain.

\section{INTRODUCCIÓN}

Las cianobacterias bentónicas de arroyos y ríos constituyen una comunidad bien desarrollada aunque muy poco conocida y estudiada, siendo bastante escasos los trabajos publicados en este campo (Rott y Pfister, 1988; Cantonati et al.,
1996; Plenkovic-Moraj, 1996) a diferencia de la presencia de cianobacterias en otros medios, como son los embalses, donde actualmente están siendo más estudiadas (Oliver \& Ganf, 2000; Sanchis et al., 2002). Sin embargo, las cianobacterias son una parte importante del bentos de ríos, en especial en aquellos de pHs alcalinos 
(Whitton, 2000), aunque están también presentes en ríos de naturaleza silícica (Heuff y Horkan, 1984) siendo por ello en los primeros donde se centran la mayoría de los estudios existentes. En España en general, son muy escasos los trabajos publicados en este campo y en ocasiones forman parte de estudios más genéricos que comprenden el estudio de toda la flora algal (González Guerrero, 1944; Margalef, 1952, 1953; Aboal, 1988, 1989; Sabater et al., 1990). La metodología empleada en estos estudios se basa generalmente en estudios florísticos llevados a cabo sobre la observación de muestras fijadas o directamente del material vivo (Rott y Pfister, 1988). Sin embargo, algunas especies pueden pasar desapercibidas bien por su baja frecuencia bien porque se encuentren en formas de resistencia en el momento de la recogida, de manera que estas metodologías pueden dar resultados incompletos, pudiendo el empleo de cultivos contribuir positivamente en este tipo de trabajos (Perona et al., 2003). Las cianobacterias desempeñan un papel importante en las comunidades, habiendo sido utilizadas en ocasiones como bioindicadores de calidad del agua (Perona et al., 1998; Douterelo, 2000) e incluso, en la actualidad, se está estudiando la toxicidad de estas comunidades sobre diatomeas y macroinvertebrados (Aboal et al., 2002). Por ello, parece necesario e interesante el ampliar el conocimiento sobre la estructura y composición de estas comunidades bentónicas en ríos. Así, el objetivo del presente trabajo es conocer la composición de la comunidad de cianobacterias bentónicas en un arroyo de montaña mediterráneo de características silícicas y con escasas perturbaciones antrópicas, utilizando para ello dos metodologías diferentes: crecimiento en cultivos y observación de muestras fijadas.

\section{ÁREA DE ESTUDIO}

El arroyo Mediano discurre por la sierra de Guadarrama, en la vertiente Sur del Sistema Central. Administrativamente se encuentra en la Comunidad Autónoma de Madrid, y dentro de ella, en el Parque Regional de la Cuenca Alta

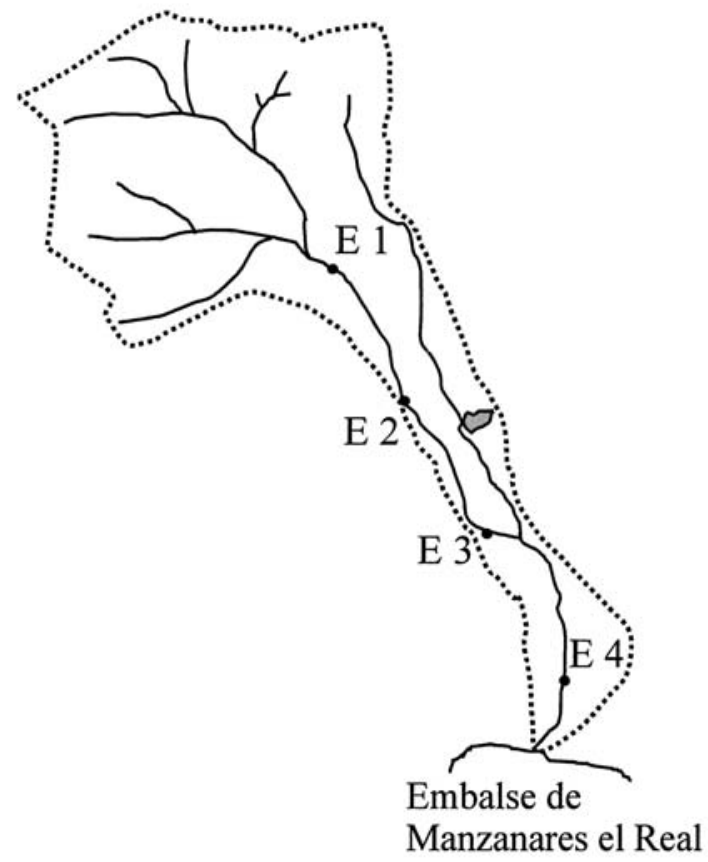

Figura 1. Cuenca del arroyo Mediano (Madrid) y situación geográfica de las estaciones de muestreo. Escala = $1 \mathrm{~km}$. Water basin of Mediano stream (Madrid) and location of sampling points. Scale $=1 \mathrm{~km}$. 
del río Manzanares. Nace en un manantial a $1970 \mathrm{~m}$ de altitud y desemboca a $894 \mathrm{~m}$ de altitud en el embalse de Manzanares el Real (Figura 1). Recorre una longitud de 11 kilómetros, con un desnivel total de $1076 \mathrm{~m}$. Es un arroyo que posee todas las características típicas de un sistema montañoso y de clima mediterráneo, con alternancia de rápidos y remansos, donde su caudal se ve afectado por el deshielo primaveral y el estiaje veraniego. El lecho del arroyo es rocoso y está formado por rocas y gravas de materiales predominantemente silíceos. En su parte inferior atraviesa una zona de materiales más calizos que contrasta con la parte alta del arroyo, puramente granítica.

\section{MATERIALES Y MÉTODOS}

\section{Muestreos}

Se localizaron 4 estaciones de muestreo a lo largo del arroyo Mediano (Fig. 1) que se muestrearon estacionalmente durante el año 1998. En los muestreos se analizaron in situ algunas características del agua $(\mathrm{pH}$, oxígeno disuelto, conductividad, temperatura) y se recogieron en cada estación de muestreo tres rocas del lecho del río para el estudio de la comunidad de cianobacterias bentónicas que se conservaron a $4{ }^{\circ} \mathrm{C}$ hasta la extracción de la comunidad (generalmente menos de 4 horas). Paralelamente se recogieron muestras de agua en botes de polipropileno de boca ancha para el análisis químico (todo el material para los análisis químicos se lavó previamente con $\mathrm{HCl}$ al $10 \%$ ).

El pH se midió con un electrodo portátil WTW pH-96, el $\mathrm{O}_{2}$ disuelto y la temperatura del agua con un oxímetro portátil WTW Oxi-196 y la conductividad con un conductivímetro CRISON CDTM-523 (previamente calibrados). Los análisis químicos del agua se realizaron (por diplicado) con un laboratorio portátil DREL 2000 de $\mathrm{HACH}$, analizando nitrógeno inorgánico disuelto

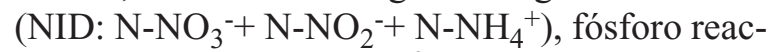

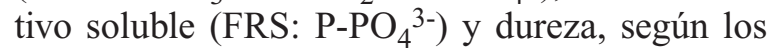
métodos descritos en Perona et al. (1999a).

\section{Análisis de laboratorio}

Las cianobacterias bentónicas se separaron de la roca mediante el cepillado de una superficie de $16 \mathrm{~cm}^{2}$ de ésta y posterior resuspensión de los extractos en medio de cultivo BG11 $1_{0}$. Una alícuota de dicho extracto $(0.3 \mathrm{ml})$ se sembró en placas Petri con medio de cultivo y agar-agar al $1.5 \%$, siguiendo el método de diluciones de Rippka (1988) para observar los especímenes de cianobacterias que crecen sobre ellas, el resto del extracto se fijó con formaldehido a una concentración final del $4 \%$ y se mantuvieron en frío y oscuridad (para evitar pérdidas de pigmentación) hasta la observación de las especies. Los medios de cultivo empleados fueron BG11 y BG11 $1_{0}$ (pH 7.6 tamponado con HEPES $20 \mathrm{mM}$ ) (con y sin fuente de $\mathrm{N}$ combinada respectivamente) para seleccionar el crecimiento de especies no fijadoras y fijadoras de $\mathrm{N}_{2}$. Los cultivos se mantenían por un período de 3-4 semanas en un incubador de placas, en luz continua (15$\left.20 \mu \mathrm{E} \mathrm{m}^{-2} \mathrm{~s}^{-1}\right)$ y temperatura constante $\left(28^{\circ} \mathrm{C}\right)$

La riqueza específica de cianobacterias en las distintas estaciones de muestreo se ha estudiado utilizando de forma conjunta la observación de los extractos fijados y las cianobacterias crecidas en los cultivos. En el estudio de la riqueza específica de las muestras fijadas se utilizó una cámara Neubauer, observando al microscopio óptico todos los compartimentos de la misma (esta operación se realizaba por triplicado para cada muestra). Se observaron las colonias de cianobacterias crecidas en placas tanto a la lupa binocular como al microscopio, utilizando técnicas de campo claro, contraste de fases y epifluorescencia para la determinación de las especies, midiendo un mínimo de 10 veces las dimensiones de las mismas. Para la determinación taxonómica se utilizaron las claves botánicas de Geitler (1932), Desikachary (1959), Starmach (1966), Komárek y Anagnostidis (1999) así como las revisiones de Anagnostidis y Komárek (1988) y Komárek y Anagnostidis (1989).

El porcentaje de presencias de cada cianobacteria se ha calculado según el $\%$ de veces que ha sido observada en el total de casos que presenta 
Tabla 1. Características físico-químicas del agua del arroyo Mediano en los tres tramos estudiados (en rangos máximo y mínimo de variación y valores medios). ( $\mathrm{NID}=$ Nitrógeno Inorgánico Disuelto, FRS= Fósforo Reactivo Soluble). Water physico-chemical variables in Mediano stream in the three studied stretch (maximun and minimun range and media values). (NID=Dissolved Inorganic Nitrogen, FRS $=$ Soluble Reactive Phosphorus).

\begin{tabular}{|c|c|c|c|c|}
\hline \multicolumn{2}{|l|}{ Parámetro (unidades) } & \multirow{2}{*}{$\begin{array}{c}\underset{\mathbf{n}=\mathbf{8}}{\text { TRAMO ALTO }} \\
1\end{array}$} & \multirow{2}{*}{$\begin{array}{l}\text { TRAMO MEDIO } \\
\mathbf{n}=\mathbf{1 6} \\
2-3\end{array}$} & \multirow{2}{*}{$\begin{array}{c}\underset{\mathbf{n}=\mathbf{8}}{\text { TRAMO BAJO }} \\
4\end{array}$} \\
\hline Estación & & & & \\
\hline \multirow{2}{*}{$\mathrm{pH}$} & Rango & $5.4-6.3$ & $5.2-7.0$ & $6.0-7.0$ \\
\hline & media & 6.01 & 6.44 & 6.60 \\
\hline \multirow[t]{2}{*}{$\mathrm{T}^{\mathrm{o}}$ agua $\left({ }^{\circ} \mathrm{C}\right)$} & Rango & $5.9-16.9$ & $5.6-18.6$ & $6.1-17.6$ \\
\hline & media & 11.53 & 11.21 & 12.58 \\
\hline \multirow[t]{2}{*}{ Conductividad $(\mu \mathrm{S} / \mathrm{cm})$} & Rango & $15.5-27.6$ & $16.7-56.1$ & $19.1-476.6$ \\
\hline & media & 23.01 & 27.37 & 209.83 \\
\hline \multirow[t]{2}{*}{ Dureza $\left(\mathrm{mg} / \mathrm{CaCO}_{3}\right)$} & Rango & $4.1-8.83$ & $4.9-14.0$ & $13.2-201.6$ \\
\hline & media & 5.88 & 9.46 & 99.63 \\
\hline \multirow[t]{2}{*}{$\mathrm{O}_{2}(\mathrm{mg} / \mathrm{l})$} & Rango & $8.06-10.43$ & $4.9-10.7$ & $1.16-9.60$ \\
\hline & media & 9.38 & 7.80 & 5.91 \\
\hline \multirow{2}{*}{$\mathrm{O}_{2}(\%$ saturación $)$} & Rango & $93.9-101$ & $52.0-98.3$ & $12.3-91.0$ \\
\hline & media & 96.07 & 78.80 & 58.58 \\
\hline \multirow[t]{2}{*}{ NID (mg/l) } & Rango & $0.02-0.186$ & $0.028-0.283$ & $0.124-0.531$ \\
\hline & media & 0.128 & 0.145 & 0.478 \\
\hline \multirow[t]{2}{*}{ FRS (mg/l) } & Rango & $0.033-0.115$ & $0.005-0.180$ & $0.035-0.118$ \\
\hline & media & 0.058 & 0.050 & 0.070 \\
\hline
\end{tabular}

el estudio ( $n=16,4$ puntos y 4 muestreos, uno en cada estación climatológica).

\section{RESULTADOS Y DISCUSIÓN}

El arroyo Mediano se caracterizó por presentar generalmente aguas claras, de temperaturas bajas y bien oxigenadas, típicas de regiones de montaña, con muy baja conductividad, $\mathrm{pH}$ ligeramente ácido a neutro y con concentraciones de nutrientes entre bajas y moderadas (Tabla 1). En función de las variaciones en las características del agua, que pueden verse reflejadas en la misma Tabla 1, se ha dividido el arroyo en tres tramos o secciones diferenciadas: Tramo alto o curso alto (que incluye la estación 1), caracterizado por su elevada pendiente, un lecho rocoso formado por grandes bloques de roca, aguas con temperaturas bajas, muy buena oxigenación (98\%), baja mineralización y escasez de nutrientes; un tramo medio o curso medio, formado por las estaciones de muestreo 2 y 3 , con pendientes más suaves y un leve incremento en las características hidro- químicas, conductividad, NID y FRS y un descenso en la oxigenación de las aguas con un valor medio de $78 \%$; por último la estación 4 , constituye el tramo o curso bajo, caracterizado por muy poca pendiente y formación de pozas, y donde se observan los mayores valores para todas las variables medidas, con excepción del oxígeno disuelto para el cuál los valores fueron los más bajos (valor medio de 58\%) (Tabla1).

A la vista de los resultados, el arroyo Mediano parece presentar características típicas de un arroyo de montaña sin alteraciones de tipo humano, ya que mantiene valores de baja conductividad, buena oxigenación y bajo o moderado contenido en nutrientes, similares a los observados por Cantonati et al. (1996) en arroyos de montaña de la cuenca del río Sarca (Italia), con ligeros incrementos en la mineralización y nutrientes en los tramos medio y bajo, como suele ser habitual en todos los ríos (Margalef, 1983), aunque no tan acusados como los observados en el río Alberche (Perona et al., 1999a) al no presentar el arroyo Mediano procesos de eutrofización. 
Tabla 2. Listado de cianobacterias encontradas en el arroyo Mediano, tipo de muestra y porcentaje de observaciones para cada una de las especies $(\mathrm{n}=16)$. List of cyanobacteria found in Mediano stream, sample kind and percentage of observation of each cyanobacterium ( $n=16)$.

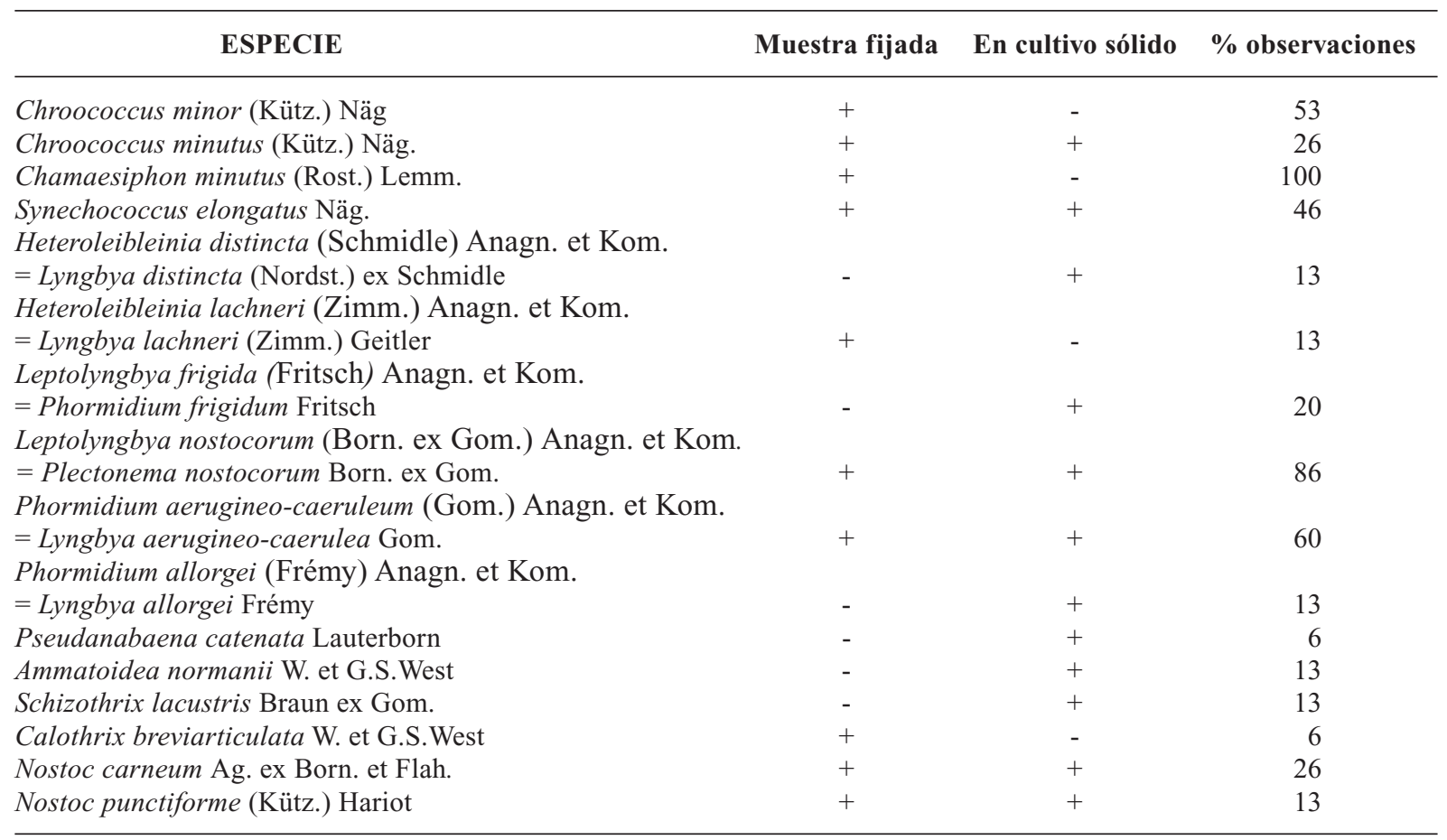

\section{Composición de la comunidad del arroyo Mediano}

La comunidad de cianobacterias bentónicas observadas en el arroyo Mediano está compuesta por un total de 16 especies que se describen a continuación. En la Tabla 2 se muestra el listado de especies y el tipo de muestra (fijada o en cultivo) en el que se fueron observadas.

\section{ORDEN CHROOCOCCALES}

\section{Chamaesiphon minutus (Rostafinski)}

\section{Lemmermann 1910}

Se observó exclusivamente en las muestras fijadas, nunca en cultivos. Presenta al microscopio células alargadas de aproximadamente $1.5 \mu \mathrm{m}$ de diámetro y de hasta $5 \mu \mathrm{m}$ de longitud con ambos extremos redondeados. Pseudovagina muy poco visible.

Es una cianobacteria típica de zonas de montaña (Komárek \& Anagnostidis, 1999) y es muy representativa en todo el curso del arroyo Mediano.
Chroococcus minor (Kützing) Nägeli 1949

Colonias microscópicas de células reunidas en grupos de 2 a 4 células, recubiertas de un mucílago muy fino e incoloro, a veces difícilmente visible. Células esféricas de 0.8 a $1 \mu \mathrm{m}$ de diámetro y de color verde-azulado.

Se ha observado en las muestras fijadas y no creció en las placas con medio de cultivo (Tabla 2). Ha sido descrita como una cianobacteria típica de ríos y arroyos, entre otros sistemas (Komárek \& Anagnostidis, 1999). Ha sido previamente descrita en aguas dulces españolas por González Guerrero (1944). Es una cianobacteria también muy representativa del arroyo Mediano, habiéndose observado en todo el curso del arroyo.

Chroococcus minutus (Kützing) Nägeli 1949 El cultivo presentó una colonia microscópica y gelatinosa; las células tienen forma ligeramente oval de $3.7 \times 6.5 \mu \mathrm{m}$ reunidas en grupos de $2 \mathrm{a}$ 4 células y recubiertas de un mucílago que puede 
llegar a alcanzar $14 \mu \mathrm{m}$ de diámetro. Ha sido encontrada también en ríos calcáreos del SE de España (Aboal, 1988) en aguas más eutróficas, así como vista en charcos y en el río Torio (León) por González Guerrero (1944). Es también una de las cianobacterias típicas del estudio, apareciendo en todos los tramos del río definidos.

\section{Synechococcus elongatus Nägeli 1849}

Células cilíndricas de $1.6 \mu \mathrm{m}$ de diámetro medio y 2.2 a $3 \mu \mathrm{m}$ de longitud. En cultivo se llegaron a observar pequeñas cadenas de hasta 4 células. Observada en todas las muestras tanto fijadas como en cultivo. Es muy típica de ambientes húmedos y litorales de arroyos y lagos (Komárek \& Anagnostidis, 1999) y ha sido observada en ambientes similares en España, en sustratos sumergidos y canales (Aboal, 1996). En el arroyo Mediano aparece en todo su curso y es una de las especies más representativas del arroyo.

\section{ORDEN OSCILLATORIALES}

\section{Heteroleibleinia lachneri (Zimm.)}

Anagnostidis et Komárek 1988

= Lyngbya lachneri (Zimm.) Geitler 1932

El especimen presenta filamentos de 3.8- $4.4 \mu \mathrm{m}$ de diámetro, incluso, en ocasiones hasta $5 \mu \mathrm{m}$. Vaina incolora y separada del tricoma. Células de 2.2 a $2.7 \mu \mathrm{m}$ de ancho y muy cortas (1.1- $2.2 \mu \mathrm{m})$, claramente constrictas. La célula final presenta un tamaño mayor y de aspecto puntiagudo. Observada tanto en muestras fijadas como en cultivo pero de forma esporádica. Es una cianobacteria típica de pequeños arroyos (Desikachary, 1959) y en el arroyo Mediano la hemos observado en las estaciones del curso alto y bajo.

\section{Heteroleibleinia distincta (Schmidle)}

Anagnostidis et Komárek 1988

= Lyngbya distincta (Nordst.) Schmidle 1896

Especimen observado únicamente en cultivo (Tabla 2), presentando una colonia extendida sobre el agar, de filamentos que presentan diámetros muy distintos. Los filamentos presentan una vaina fina e incolora de 2 a $3.5 \mu \mathrm{m}$ de diámetro. Células de 1.5 a $2.2 \mu \mathrm{m}$ de ancho y desde isodiamétricas a en ocasiones muy alargadas (2-
3-6 $\mu \mathrm{m})$. Aparece en los tramos medio y bajo del arroyo Mediano.

\section{Leptolyngbya frigida (Fritsch)}

Anagnostidis et Komárek 1988

= Phormidium frigidum Fritsch 1921

Filamentos de color verde-azulado extendidos en el agar, ligeramente curvados, envueltos por una vaina muy fina e incolora, alcanzando unas dimensiones de 1.6 a $2.2 \mu \mathrm{m}$ de ancho. Tricomas de células ligeramente alargadas, de 1.1-1.6 $\mu \mathrm{m}$ de ancho y (1-) 2.2 - $3 \mu \mathrm{m}$ de largo, con gránulos de cianoficina en la unión de los septos.

Sólo fue observada en los cultivos de las muestras recogidas; aparece a lo largo de todo el curso del arroyo a excepción de la estación 3.

\section{Leptolyngbya nostocorum (Born. ex Gom.)} Anagnostidis et Komárek 1988

= Plectonema nostocorum Born. ex Gom. 1892 Colonias finas y extendidas sobre el cultivo agarizado, de filamentos de 1.7 a $3 \mu \mathrm{m}$ de diámetro. Vaina incolora y claramente separada del tricoma. Células de $0.8 \mu \mathrm{m}$ de diámetro (en ocasiones de $1.2 \mu \mathrm{m}$ ), isodiamétricas en su mayoría, aunque en ocasiones más alargadas 0.8-1.4 (-3) $\mu \mathrm{m}$.

Se observó en todo tipo de muestras y crece muy bien sobre el agar. Es una de las cianobacterias más comunes del arroyo Mediano, apareciendo en la totalidad de las zonas estudiadas. Ha sido encontrada también en otros ríos de la región (río Alberche, Perona et al., 1999b), así como en otros ríos de la provincia de Madrid (Douterelo, 2000; Sánchez-García, 2002; Rodríguez-Gómez V. com. per.) lo que parece indicar que es muy típica en las comunidades bentónicas de estos ríos.

\footnotetext{
Phormidium aerugineo-caeruleum (Gomont)

Anagnostidis et Komárek 1988

= Lyngbya aerugineo-caerulea Gomont 1892

Cianobacteria observada en numerosas ocasiones en el arroyo, incluso se han podido ver grandes tapetes mucilaginosos y oscuros (de aproximadamente $2 \mathrm{~mm}$ de espesor) recubriendo las rocas del lecho del arroyo. Al microscopio son filamentos rectos de 6.1 a $7 \mu \mathrm{m}$ de diámetro, provistos de una vaina incolora, un tricoma de
} 

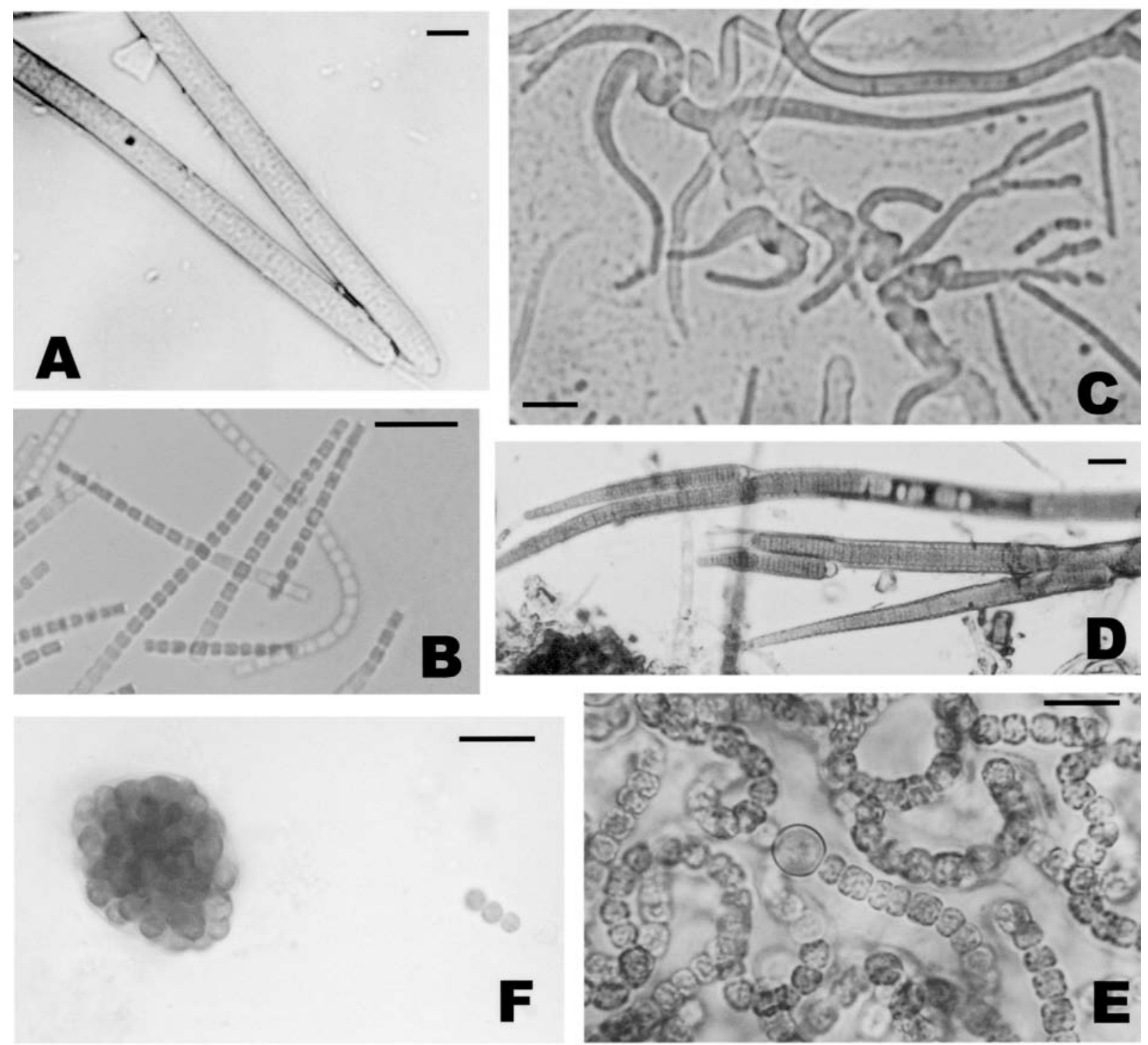

Figura 2. Microfotografías de algunas cianobacterias del arroyo Mediano. Microphotographs of some cianobacteria of Mediano stream.

A. Phormidium aerugineo-caeruleum B. Pseudanabaena catenata C. Ammatoidea normanii D. Calothrix breviarticulata E. Nostoc carneum y F. Nostoc punctiforme $($ Escala $=10 \mu \mathrm{m})$. Microphotographs of some cyanobacteria of Mediano stream: A. Phormidium aerugineo-caeruleum $\boldsymbol{B}$. Pseudanabaena catenata $\boldsymbol{C}$. Ammatoidea normanii $\boldsymbol{D}$. Calothrix breviarticulata $\boldsymbol{E}$. Nostoc carneum and $\boldsymbol{F}$. Nostoc punctiforme $($ Scale bar $=10 \mu \mathrm{m})$.

5.5 a $6.1 \mu \mathrm{m}$ de diámetro y células generalmente cortas, de 2.7 a $3.3 \mu \mathrm{m}$ (Fig. 2A)

Aparece en los tres tramos del arroyo definidos y ha sido identificada además de en las muestras fijadas, en cultivo (Tabla 2). Formando masas sobre las piedras se observó exclusivamente en la estación 1. Además se la ha podido observar en la base de colonias de Nostoc punc- 
tiforme. Aboal (1988) la observó sobre musgos en una fuente del SE de España.

\section{Phormidium allorgei (Frémy)}

Anagnostidis et Komárek 1988

= Lyngbya allorgei Frémy 1930

Filamentos solitarios, en algunas ocasiones formando una colonia tipo césped sobre el medio de cultivo agarizado, poco curvados, de 3.3 a $5 \mu \mathrm{m}$ de diámetro, con una vaina fina que contiene un tricoma con células no constrictas de $3 \mu \mathrm{m}$ de diámetro y de $1.8-3 \mu \mathrm{m}$ de longitud, desde más aplanadas a formas isodiamétricas. Célula final de aspecto redondeado. Ha sido observada mayoritariamente en la zona baja del arroyo Mediano, estaciones 2 y 3, ya que las rocas sumergidas en aguas corrientes son uno de sus sustratos habituales (Desikachary, 1959).

\section{Pseudanabaena catenata Lauterborn 1932}

Tricoma formado por células cilíndricas de color verdeazulado típico, con presencia de aerotopos. Diámetro celular $1.9 \mu \mathrm{m}$ y $2.3 \mu \mathrm{m}$ de longitud (Fig. 2B). Ha sido observada en el tramo bajo del arroyo Mediano y junto a filamentos de Phormidium aerugineo-caeruleum.

Ammatoidea normanii W. et G.S. West 1897 Observada únicamente sobre los cultivos sólidos (Tabla 2) presentando filamentos extendidos sobre el agar formando una especie de césped complejo. Los filamentos presentan diversas morfologías, desde filamentos rectos a un poco curvados e incluso retorcidos o enrollados sobre sí mismos, formando en ocasiones ramificaciones en forma de V. Por lo general hay un único tricoma por vaina, pero en ocasiones se han visto varios. El diámetro del filamento llega hasta $7.2 \mu \mathrm{m}$ (Fig. 2C). Células del tricoma mayoritariamente discoidales de $4.6 \mu \mathrm{m}$ de diámetro y de longitud media de 1.7 - $2 \mu \mathrm{m}$; algunas células tienen forma esférica de $4 \mu \mathrm{m}$ de diámetro.

Ha sido encontrada en las estaciones 2 del tramo medio y 4 del tramo bajo, pero de forma muy puntual. Fue citada por primera vez para España en los canales de irrigación del SE de España (Aboal, 1996).
Schizothrix lacustris Braun ex Gommont 1892 El especimen presenta filamentos de vaina muy ancha y fina y en ocasiones coloreada de verde a marrón, de 4 a $6 \mu \mathrm{m}$ de ancho, que contienen un tricoma muy fino de $1-1.5 \mu \mathrm{m}$ de ancho y de células isodiamétricas en su mayoría, alcanzando algunas $2.5(-3) \mu \mathrm{m}$ de longitud.

Ha sido observada sólo en cultivos y en el tramo medio del arroyo, estaciones 2 y 3.

\section{ORDEN NOSTOCALES}

Calothrix breviarticulata Welwitsch et G.S.

West 1897

Los filamentos que presenta el especimen estudiado son atenuados, de diámetro 13-15 $\mu \mathrm{m}$, en la base. Diámetro medio del tricoma 8.5 y una longitud celular de 1.5-2.8 (-3) (Fig. 2D). Vaina ligeramente lamelada. Fue observada en una única ocasión, formando masas de filamentos sobre una superficie de plástico sumergida en la estación 1.

Nostoc carneum Agardh ex Bornet et Flahault 1888

Colonia sobre el agar de aspecto rugoso, viscoso y de color verde oliva. Al microscopio, se observan filamentos ligeramente curvados de células esféricas hasta oblongas de 4-4.2 $\mu \mathrm{m}$ de diámetro y 4-4.5-(5) $\mu \mathrm{m}$ de longitud. Heterocitos de 4.1-5 $\mu \mathrm{m}$ de diámetro y $5.7 \mu \mathrm{m}$ de longitud (Fig. 2E). Acinetos grandes, oblongos de $5.3 \mu \mathrm{m}$ de ancho y hasta $8 \mu \mathrm{m}$ de largo.

Se ha observado tanto en las muestras fijadas como en los cultivos (Tabla 2), y en toda la longitud del arroyo Mediano.

Nostoc punctiforme (Kützing) Hariot 1981 Colonias esféricas de superficie lisa sobre el agar, de aspecto mucilaginoso y de color desde verde oliva a verde oscuro casi negro. Sobre las rocas se observaron en ocasiones colonias redondas y planas de color negro de aproximadamente $2 \mathrm{~mm}$ de diámetro. Al microscopio se observan masas densas de filamentos envueltos en una vaina. Células casi esféricas con un diámetro medio $4.3 \mu \mathrm{m}$ (Fig. 2F), con heterocitos sobresaliendo de esas masas, semiesféricos y 
con un diámetro de $4.2 \mu \mathrm{m}$ y una longitud de $3 \mu \mathrm{m}$. Los acinetos presentan forma elipsoidal, de $5 \mu \mathrm{m}$ de diámetro y $6.3 \mu \mathrm{m}$ de largo. Se ha observado tanto en muestras fijadas como en cultivos, siendo más abundante en el curso alto y medio del arroyo. Se ha visto en otros ríos Españoles, como el río Benamor (Aboal, 1988) o el río Alberche (Perona et al., 2003).

\section{Estructura de la comunidad}

La estructura de la comunidad de cianobacterias se muestra en la figura 3. Los datos de la totalidad de especies del arroyo Mediano, más de la mitad de las especies pertenecen al orden de las Oscillatoriales (9 especies) mientras que los órdenes Chroococcales y Nostocales, tienen muy poca representación (4 y 3 especies respectivamente), siendo las Oscillatoriales por tanto las que presentan mayor variedad. En los tramos medio y bajo ya definidos en el arroyo Mediano, no hay grandes diferencias de la riqueza específica de cianobacterias con respecto al tramo alto, ligeramente inferior. La presencia de Chroococcales es constante en todo el arroyo, mientras que en los tramos medio y bajo se aprecia un ligero incremento de Oscillatoriales y un descenso de Nostocales con respecto a lo que presenta el tramo alto.

Al observar el porcentaje de veces en las que se han observado cada cianobacteria en las estaciones de muestreo (bien en muestra fijada o en cultivo) (Tabla 2), la importancia de esos órdenes se muestra diferente, siendo el orden Chroococcales el mejor representado en todas sus especies. Las especies que componen la comunidad del arroyo se pueden clasificar en dos clases, en función del número de estaciones en las que se han visto. Un primer grupo de "especies comunes" como aquellas especies que aparecen en más del $25 \%$ de los casos, que son las más representativas de la comunidad de dicho arroyo, constituido por 7 especies; y un segundo grupo de "especies raras", que aparecen con una presencia puntual y esporádica $(<25 \%$ de los casos), formado por 9 especies.

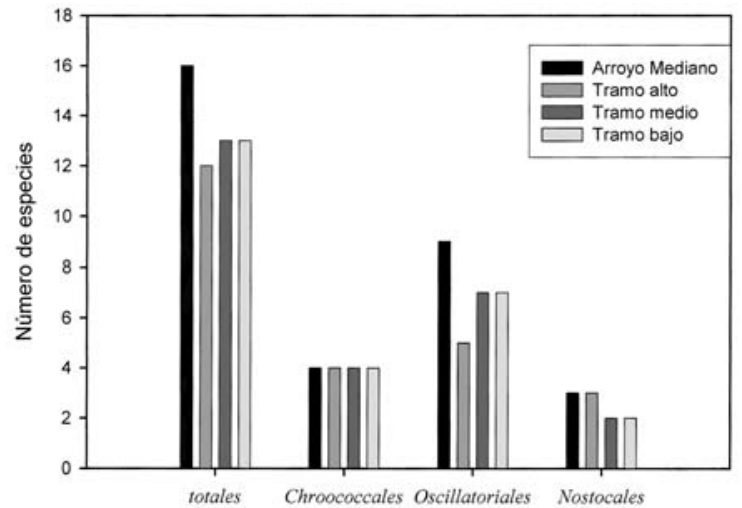

Figura 3. Riqueza específica de cianobacterias bentónicas en el arroyo Mediano distribuidas en los diferentes órdenes taxonómicos y en los 3 tramos del arroyo definidos. Benthic cyanobacteria species richness distributed in each taxonomical order and in each defined stretch in Mediano stream.

Cianobacterias "comunes" el arroyo Mediano son las 4 especies Chroococcales (Chamaesiphon minutus, Chroococcus minor, C. minutus y Synechococcus elongatus) junto a Leptolyngbya nostocorum, Phormidium aerugineo-caeruleum y Nostoc carneum siendo el resto especies del grupo de cianobacterias de distribución "rara". En este arroyo son las Chroococcales las más representativas en la comunidad. Acs y Kiss (1991) observaron también una mayor riqueza de este orden frente a las Nostocales en el río Danubio, sin embargo en el río Alberche fueron éstas últimas las más variadas debido a que se ven favorecidas por los cambios de caudal del río (Perona, 1996). La mayoría de las "especies comunes" que hemos encontrado en el arroyo Mediano han sido descritas formando parte de la comunidad cianobacteriana de otros ríos. Chroococcus minutus ha sido encontrado en ríos croatas (PlenkovicMoraj, 1996) y en la cuenca del río Segura tanto en aguas dulces como salobres (Aboal, 1988) al igual que Chroococcus minor. Chamaesiphon minutus se ha encontrado en arroyos alpinos silícicos del río Caragh (Irlanda) (Heuff \& Horkan, 1984), al igual que otras especies de este género que forman parte importante de las comunidades bénticas sobre todo en arroyos y surgencias de montaña de terrenos silícicos del río Sarca (Italia) (Cantonati et al., 1996). 
La riqueza específica observada en el arroyo Mediano, es similar a la vista en estaciones no contaminadas de ríos de esta región (Perona et al., 1999b; Douterelo, 2000) pero sin embargo inferiores a la observada en ríos calcáreos (Aboal, 1989) como es de esperar dada la preferencia de cianobacterias por los medios alcalinos. La comunidad que presenta el arroyo Mediano es muy similar en composición y estructura a la observada en el río Caragh (Irlanda) (Heuff y Horkan, 1984), siendo éste un río también de zonas altas de montaña con abundancia en algas, en especial por cianobacterias, aunque influenciado por un clima oceánico y no mediterráneo como es el arroyo Mediano.

Por último, en la Tabla 2 podemos ver que no todas las especies han sido observadas en las muestras fijadas y en los cultivos. Podemos observar que el $37 \%$ de las especies definidas en la comunidad de cianobacterias del arroyo Mediano no se observaron en las muestras fijadas aunque crecieron sobre los cultivos de agar, perteneciendo todas ellas al grupo de las consideradas "raras" y del orden oscillatoriales, lo que permitió su catalogación e identificación. Sin embargo, los cultivos tampoco nos permiten observar la totalidad de la comunidad, ya que un $25 \%$ de las especies encontradas en las muestras fijadas no crecieron en los cultivos sólidos, debido a que los requerimientos de algunas especies son a veces específicos y las condiciones de cultivo empleadas no fueron idóneas para el crecimiento de dichas especies como es bien conocido (Rippka, 1988; Thiel et al., 1989). Hay que tener en cuenta que la mayoría de los trabajos florísticos se realizan sobre la observación directa de muestras recogidas en campo, ya sean fijadas o no, y que según estos resultados y los obtenidos en estudios de cianobacterias bentónicas en otros ríos de la Comunidad de Madrid (SánchezGarcía, 2002; Perona et al., 2003), el estudio simultáneo de cultivos y de muestras fijadas nos ha permitido un mejor conocimiento de las poblaciones de cianobacterias bentónicas presentes en dichos ríos así como facilitar la identificación en especial en aquellos de ambientes silícicos donde las comunidades no son demasiado conspicuas (siempre teniendo en cuenta las diferentes formas que pueden adoptar en los cultivos). En el arroyo Mediano de no haber procedido así se hubiera perdido el $50 \%$ de la información de especies de distribución "rara", que a pesar de tener una distribución muy puntual forman parte de la comunidad, de manera que proponemos el empleo en paralelo de ambos tipos de técnicas para obtener un conocimiento más amplio de las comunidades de cianobacterias bentónicas de ríos en especial en los silícicos.

\section{AGRADECIMIENTOS}

Gracias a la Dra. Carmen Casado y al Dr. Salvador Mollá por introducirnos al estudio del arroyo Mediano y a la Dra. Marina Aboal por la ayuda en la identificación de algunas especies. Este trabajo fue subvencionado por los proyectos de la DGICYT (PB 96-1113) y CICYT (REN 20001021-CO3-O3) y una beca de la Universidad Autónoma de Madrid para Alberto Serrano.

\section{BIBLIOGRAFÍA}

ABOAL, M. 1988. Aportación al conocimiento de las algas epicontinentales del sudeste de España. III: Cianofíceas (Cyanophyceae Schaffner 1909). Anales del Jardín Botánico de Madrid, 45: 3-46.

ABOAL, M. 1989. Epilithic algal communities from River Segura Basin, Southeastern Spain. Arch. Hydrobiol., 116: 113-124.

ABOAL, M. 1996. Epipelic algal communities in irrigation channels of Southeastern Spain. Algological Studies, 82: 117-130.

ABOAL, M., M. A. PUIG, P. MATEO \& E. PERONA. 2002. Implications of cyanophyte toxicity on biological monitoring of calcareous streams in northeast Spain. J. appl. Phycol., 14: 49-56.

ACS, E. \& K. T. KISS. 1991. Investigation of periphytic algae in the Danube at Göd (1669 river Km, Hungary). Algological Studies, 62: 47-67.

ANAGNOSTIDIS, K. \& J. KOMÁREK. 1988. Modern approach to the classification system of cyanophytes. 3. Oscillatoriales. Arch. Hydrobiol./ Suppl. 80 Algological Studies, 50-53: 327-472.

CANTONATI, M., E. ROTT \& E. PIPP. 1996. Ecology of cyanophytes in mountain springs of the River 
Sarca catchment (Adamello-Brenta Regional Park, Trentino, Northern Italy). Algological Studies, 83: 145-162

DESIKACHARY, T. V. 1959. Cyanophyta. Indian Council of Agricultural Research. Monographs on Algae. New Delhi, India.

DOUTERELO, I. 2000. Estudio de la calidad del agua en los ríos Guadalix, Jarama, Manzanares y Arroyo Tejada mediante el uso de bioindicadores (cianobacterias). Proyecto Fin de Carrera. Universidad Autónoma de Madrid. 178 pp.

GEITLER, L. 1932. Cyanophyceae von Europa. Kryptogamen-Flora. Akademische Verlags Gesselschaft. Leipzig.

GONZALEZ GUERRERO, P. 1944. Revisión crítica de las cianofíceas españolas de agua dulce. Anales del Jardín Botánico de Madrid, 4: 241-264.

KOMÁREK, J. \& K. ANAGNOSTIDIS. 1989. Modern approach to the classification system of Cyanophytes 4. Nostocales. Arch. Hydrobiol./Suppl. 82 Algological Studies, 56: 247-345.

KOMÁREK, J. \& K. ANAGNOSTIDIS. 1999. Cyanoprokaryota 1. Teil Chroococcales. Süßwasserflora von Mitteleuropa 19/1. H. Etts, G. Gärtner, H. Heynig \& D. Mollenhauer (eds.). Gustav Fischer, Verlag Jena, Stuttgart.

HEUFF, H. \& K. HORKAN. 1984. Caragh. In: Ecology of European Rivers. B.A.Whitton (ed.). :363-384. Blackwell Scientific Publications. London. Great Britain.

MARGALEF, R. 1952. Materiales para una flora de las algas del NE de España. IVa, Cyanophyceae. Collectanea Botánica, Vol. III Fasc. II: 10: 209-229.

MARGALEF, R. 1953. Materiales para una flora de las algas del NE de España. IVb, Cyanophyceae. Collectanea Botánica, Vol. III Fasc. II: 20: 231-260.

MARGALEF, R. 1983. Limnología. Editorial Omega, Barcelona.

OLIVER, R. L. \& G. G. GANF. 2000. Freshwater blooms. In: The ecology of cyanobacteria. The diversity in time and space. B.A.Whitton \& M.Potts (eds.): 149-194. Kluwer Academic Publishers. Dordrecht. The Netherlands.

PERONA, E. 1996. Cianobacterias epiliticas y calidad del agua del río Alberche a su paso por la Comunidad Autónoma de Madrid. Tesis Doctoral Ed. Universidad Autónoma de Madrid. Madrid. 333 p.

PERONA, E., I. BONILLA \& P. MATEO. 1998. Epilithic cyanobacteria communities and water quality: an alternative tool for monitoring eutrophication in the Alberche River (Spain). J. Appl. Phycol., 10: 183-191.
PERONA, E., I. BONILLA \& P. MATEO. 1999a. Spatial and temporal changes in water quality in a Spanish river. Sci. Tot. Environ., 241: 75-90.

PERONA, E., I. BONILLA \& P. MATEO. 1999b. Use of benthic cyanobacteria to monitor water quality in a Spanish river. In : Use of algae for monitoring rivers III. Prygiel, J., Whitton, B.A. \& Bukouska, J (eds.): 216-223. Agence de l'Eau Artois Picardie. Douai. Francia.

PERONA, E., M. ABOAL, I. BONILLA \& P. MATEO. 2003. Cyanobacterial diversity in a Spanish river determined by means of isolations of cultures. Morfological variability of isolates in relation to natural populations. Archiv für Hydrobiology/ Algological Studies, 109: (en prensa).

PLENKOVIC-MORAJ, A. 1996. Croatian freshwater cyanophyceae. Nat. Croat. 5: 299-315.

RIPPKA, R. 1988. Isolation and purification of Cyanobacteria. In: Methods in enzymology. L. Packer \& A.N. Glazer (eds.): Vol 167, Cyanobacteria. pp: 3-27. Nueva York.

ROTT, E \& P. PFISTER. 1988. Natural epilithic algal communities in fast-flowing mountain streams and rivers and some man-induced changes. Ver. Internat. Verein. Limnol., 23: 1320-1324.

SABATER, F., S. SABATER \& J. ARMENGOL. 1990. Chemical characteristics of Mediterranean river as influenced by land uses in the watershed. Water Res., 24: 373-382.

SÁNCHEZ-GARCÍA, L. 2002. Monitorización de la calidad del agua de los ríos Jarama y Guadalix a su paso por la Comunidad de Madrid. Proyecto Fin de Carrera, Universidad Autónoma de Madrid, $205 \mathrm{pp}$.

SANCHIS, D., D. CARRASCO, C. PADILLA, F. LEGANÉS, E. FERNÁNDEZ-VALIENTE, F. DEL CAMPO \& A. QUESADA. 2002. Spatial and temporal heterogeneity in succesion of cyanobacterial blooms in a Spanish reservoir. Ann. Limnol., 38 (3): 173-183

STARMACH, K. 1966. Cyanophyta. Flora Slodkowodna Polski. Panstowe Wydawnictwo Naukowe. Varsovia.

THIEL, T., J. BRAMBLE \& S. ROGERS. 1989. Optimum conditions for growth of cyanobacteria on solid media. FEMS Microbiology Letters, 61: 27-32

WHITTON, B. A. 2000. Soils and Rice-fields. In: The ecology of cyanobacteria. The diversity in time and space. B.A.Whitton \& M.Potts (eds.):233-255. Kluwer Academic Publishers. Dordrecht. The Netherlands. 
